\title{
Acute Motor Sensory Axonal Neuropathy: A Variant of Guillain-Barré Syndrome-A Rare Case Report
}

\author{
Sanjeev K Saggar ${ }^{1}$, Richa G Thaman², Gurinder Mohan ${ }^{3}$
}

\begin{abstract}
Background: Guillain-Barré syndrome (GBS) is an immune-mediated disorder of the nervous system that shows acute or subacute onset. It is also known as Landry's paralysis. It is characterized by muscle weakness of legs and arms, limb paresthesias, and total or relative areflexia. Acute motor sensory axonal neuropathy (AMSAN) is a distinct subtype of GBS. It is not only a rare but severe variant that involves axonal degeneration in motor and sensory nerve fibers and has a prolonged recovery course.

Case description: A 60-year-old male presented to the emergency department having complaints of weakness, numbness, and tingling sensation in feet for the last fortnight, which ascended gradually towards the calves. He was observed to have a sensory disorder in hands, but not flaccid paralysis. The patient history and nerve conduction studies were indicative of AMSAN variant of GBS.

Discussion: In patients of AMSAN, the reduction of sural nerve amplitude is more pronounced as compared to acute inflammatory demyelinating polyneuropathy (AIDP) patients. In case of our patient, the electrophysiological feature indicated a more than $50 \%$ decrease in SNAP. A marked reduction in sensory nerve action potential and compound muscle action potential with only slightly decreased conduction velocities is a requirement for the diagnosis of axonal neuropathies, which is the trait seen in the reported case.

Keywords: Acute motor sensory axonal neuropathy, Compound muscle action potential, Guillain-Barré syndrome, Nerve conduction studies, Sensory nerve action potential.

AMEl's Current Trends in Diagnosis \& Treatment (2020): 10.5005/jp-journals-10055-0110
\end{abstract}

\section{INTRODUCTION}

Guillain-Barré syndrome (GBS) is an immune-mediated disorder of the nervous system that shows acute or subacute onset. It is also known as Landry's paralysis. ${ }^{1}$ It is characterized by muscle weakness of legs and arms, limb paresthesias, and total or relative areflexia $^{2}$ GBS or postinfective polyneuritis may not be a single disease but a cluster of acute neuropathies with several related immune-mediated pathogenic mechanisms. The peripheral nerves in GBS are infiltered by lymphocytes and macrophages and causes endoneural inflammation of spinal nerve roots and entrapment sites. ${ }^{3} \mathrm{GBS}$ is considered to have several variants like acute inflammatory demyelinating polyneuropathy (AIDP), acute motor axonal neuropathy (AMAN), acute motor sensory axonal neuropathy (AMSAN), and Miller-Fisher syndrome. ${ }^{4}$

Acute motor sensory axonal neuropathy (AMSAN) is a distinct subtype of GBS. It is not only a rare but severe variant that involves axonal degeneration in motor and sensory nerve fibers and has a prolonged recovery course. ${ }^{5}$ AMSAN occurs in approximately $1-15 \%$ of GBS patients. In it, a sensory disturbance is an essential feature in addition to motor symptoms and signs affecting limbs. The course of the disease is more severe and prolonged with frequent ventilator dependency, slow recovery, and significant residues. ${ }^{6-11}$

In addition to clinical features, nerve conduction study and neurophysiological variables confirm the diagnosis and allow for further categorization of a variant of GBS.

\section{Case description}

A 60-year-old male presented to the emergency department having complaints of weakness, numbness, and tingling sensation in feet for the last fortnight, which ascended gradually towards the

\footnotetext{
1,2Department of Physiology, Shri Guru Ram Das Institute of Medical Sciences and Research, Amritsar, Punjab, India

${ }^{3}$ Department of Medicine, Shri Guru Ram Das Institute of Medical Sciences and Research, Amritsar, Punjab, India

Corresponding Author: Richa G Thaman, Department of Physiology, Shri Guru Ram Das Institute of Medical Sciences and Research, Amritsar, Punjab, India, Phone: +91 9815963778, e-mail: richaghaythaman@ yahoo.co.in

How to cite this article: Saggar SK, Thaman RG, Mohan G. Acute Motor Sensory Axonal Neuropathy: A Variant of Guillain-Barré Syndrome-A Rare Case Report. MEl's Curr Trends Diagn Treat 2020;4(2):110-111.

Source of support: Nil

Conflict of interest: None
}

calves. He was observed to have a sensory disorder in hands, but not flaccid paralysis. The patient also reported that ten days ago, he suffered from mild fever and four days of self-limiting diarrhea. He did not have any respiratory disease symptoms. Moreover, there was not any history of vaccination. MRI of the brain and spine did not show any acute changes. During the second day of admission, nerve conduction studies were conducted on the patient whereby tibial, peroneal, and sural nerves were studied. These studies showed acute sensory and motor neuropathy affecting the lower limb (Table 1).

The patient history and nerve conduction studies were indicative of the AMSAN variant of GBS. Electro-diagnosed test performed revealed that the right peroneal nerve was nonstimulable while the left personal nerve showed CMAP amplitude with less than $90 \%$ of a lower limit of motor amplitude. Motor nerve 
Table 1: Nerve conduction study report of the patient

\begin{tabular}{|c|c|c|c|}
\hline $\begin{array}{l}\text { Motor nerve } \\
\text { conduction study }\end{array}$ & Latency (ms) & Amplitude (mv) & Velocity $(\mathrm{m} / \mathrm{s})$ \\
\hline $\begin{array}{l}\text { Right tibial } \\
\text { nerve }\end{array}$ & 3.85 & $2.5^{*}$ & 38.89 \\
\hline Left tibial nerve & 3.65 & $2.9^{*}$ & 38.82 \\
\hline $\begin{array}{l}\text { Right peroneal } \\
\text { nerve }\end{array}$ & \multicolumn{3}{|c|}{ Non-stimulable } \\
\hline $\begin{array}{l}\text { Left peroneal } \\
\text { nerve }\end{array}$ & 3.85 & $1.5^{*}$ & 39.08 \\
\hline $\begin{array}{l}\text { Sensory nerve } \\
\text { conduction study }\end{array}$ & Latency (ms) & Amplitude ( $\mu v)$ & $\begin{array}{l}\text { Nerve conduction } \\
\text { velocity (NCV) } \\
(\mathrm{m} / \mathrm{s})\end{array}$ \\
\hline Right sural nerve & 2.04 & $7.2^{*}$ & 43.92 \\
\hline Left sural nerve & 1.96 & $9.3^{*}$ & 46.12 \\
\hline
\end{tabular}

*Abnormally reduced value

conduction velocity was reduced mildly in both tibial and peroneal nerve bilaterally but no conduction block was visualized.

In the case of the sural nerve, SNAP amplitude was reduced bilaterally. It was less than $50 \%$ of the lower limit of normal sensory amplitude. According to NCS, neurophysiologically, there was no evidence of demyelination, i.e., latencies were unaffected. Cerebral spinal fluid (CSF) analysis was also done within two days of initial presentation. It revealed an albumin cytological disassociation with nil white cells present and an elevated protein level of $103 \mathrm{mg} / \mathrm{dL}$ against the normal value (i.e., from 45 to $60 \mathrm{mg} / \mathrm{dL}$ ).

On the third day of hospitalization, the patient was put on intravenous immunoglobulin (IVIG) therapy for the treatment of suspected AMSAN. The patient showed gradual improvement with IVIG therapy. After a hospital stay of 10 days, the patient was discharged with 4/5 power in lower limbs, 5/5 power in upper limbs, and normal sensory examination.

\section{Discussion}

This case report describes a patient of AMSAN. The patient did not have any history of diabetes or neoplastic or hematological disorder. The patient had symptoms of paresthesia along with little objective sensory loss which is considered as the most common initial symptom of GBS. This case is regarded as different because of its characteristic sensory clinical presentation, a significant decrease in amplitude of motor and sensory action potential, and mildly reduced nerve conduction velocities. Latency is unaffected indicating sparing of demyelination injury. Elevated CSF proteins as seen in this case finding are a characteristic feature in $50 \%$ of cases of GBS as also seen in other studies. ${ }^{6-12}$

Acute axonal neuropathies, such as AMAN and AMSAN are observed to have a fast progression as well as a prolonged recovery time as compared to acute demyelinating neuropathies. ${ }^{10,11}$ The clinical difference can be attributed to fundamental differences in the mechanism, as the axolemma and nodes of Ranvier are affected in AMAN and AMSAN compared to Schwan cells being affected in AIDP.
In patients of AMSAN, the reduction of sural nerve amplitude is more pronounced as compared to AIDP patients. ${ }^{12}$ In case of our patient, the electrophysiological feature indicated a more than $50 \%$ decrease in SNAP. A marked reduction in sensory nerve action potential and compound muscle action potential with only slightly decreased conduction velocities is a requirement for the diagnosis of axonal neuropathies, which is the trait seen in the reported case.

\section{Conclusion}

AMSAN is a rare variant of GBS and it can often be missed due to variations in clinical presentations. Diligent nerve conduction analysis helps in diagnosing the above variant as it presented the affected neurophysiological variables in CMAP, SNAP in unambiguous terms. Knowledge of potential clinical manifestations and clear-cut diagnosis of AMSAN is very important as it can help manage these patients and for providing counseling to their family members.

\section{References}

1. Goldman AS, Schmalstieg EJ, Freeman DH, et al. What was the cause of Franklin Delano Roosevelt's paralytic illness? J Med Biogr 2003;11(4):232-240. DOI: 10.1177/096777200301100412.

2. Gorson KC, Ropper AH. Guillain-Barré syndrome (acute inflammatory demyelinating polyneuropathy) and related disorders. In: Katirji B, Kaminski HJ, Preston DC, et al., editors. Neuromuscular disorders in clinical practice. Boston, Mass: Butterworth-Heinemann; 2002. p. 544-566.

3. Srivastava M. Nehal S, Seema N. Guillain- Barré syndrome: demographics, clinical profile and seasonal variation in a tertiary care centre of central India. Indian J Med Res 2017;145(2):203-208. DOI: 10.4103/ijmr.IJMR_995_14.

4. Hughes RAC, Cornblath DR. Guillain-Barré syndrome. Lancet 2005;366(9497):1653-1666. DOI: 10.1016/S0140-6736(05)67665-9.

5. Liu DY, Hollenbach JR, Gregorin JA, et al. A case of acute motor sensory axonal neuropathy: a variant of Guillain-Barré syndrome, with possible syndrome of irreversible lithiumeffectuated neurotoxicity, Case Rep Med 2020;2020:4683507. DOI: 10.1155/2020/4683507.

6. Chowdhury D, Arora A. Axonal Guillain-Barré syndrome: a critical review. Acta Neurol Scand 2001;103(5):267-277. DOI: 10.1034/j.16000404.2001.103005267.x.

7. Arcila-Londono $X$, Lewis R. Guillain-Barré syndrome. Semin Neurol 2012;32(3):179-186. DOI: 10.1055/s-0032-1329196.

8. Sung EJ, Kim DY, Chang MC. Prediction of functional outcome in axonal Guillain-Barré syndrome. Ann Rehabil Med 2016;40(3):481488. DOI: 10.5535/arm.2016.40.3.481.

9. Akbayram S, Akgün C, Sayin R, et al. Clinical features and prognosis with Guillain-Barré syndrome. Ann Indian Acad Neurol 2011;14(2):9899. DOI: 10.4103/0972-2327.82793.

10. Forsberg A, Press R, Holmqvist LW. Residual disability 10 years after falling ill in Guillain-Barré syndrome: a prospective follow-up study. J Neurol Sci 2012;317(1-2):74-79. DOI: 10.1016/j.jns.2012.02.026.

11. Kuwabara S, Yuki N. Axonal Guillain-Barré syndrome: concepts and controversies. Lancet Neurol 2013;12(12):1180-1188. DOI: 10.1016/ S1474-4422(13)70215-1.

12. Yadegari S, Nafissi S, Kazemi N. Comparison of electrophysiological findings in axonal and demyelinating Guillain-Barré syndrome. Iran J Neurol 2014;13(3):138-143. PMID: 25422732; PMCID: PMC4240930. 